\title{
Esophageal involvement in progressive systemic sclerosis
}

\author{
Stephen A. Geller ${ }^{a}$, Fernando P. F. de Campos ${ }^{b}$
}

Geller SA, Campos FPF. Esophageal involvemnt in progressive systemic sclerosis. Autopsy Case Rep [Internet]. 2013; 3(3): 77-79. http://dx.doi.org/10.4322/acr.2013.031

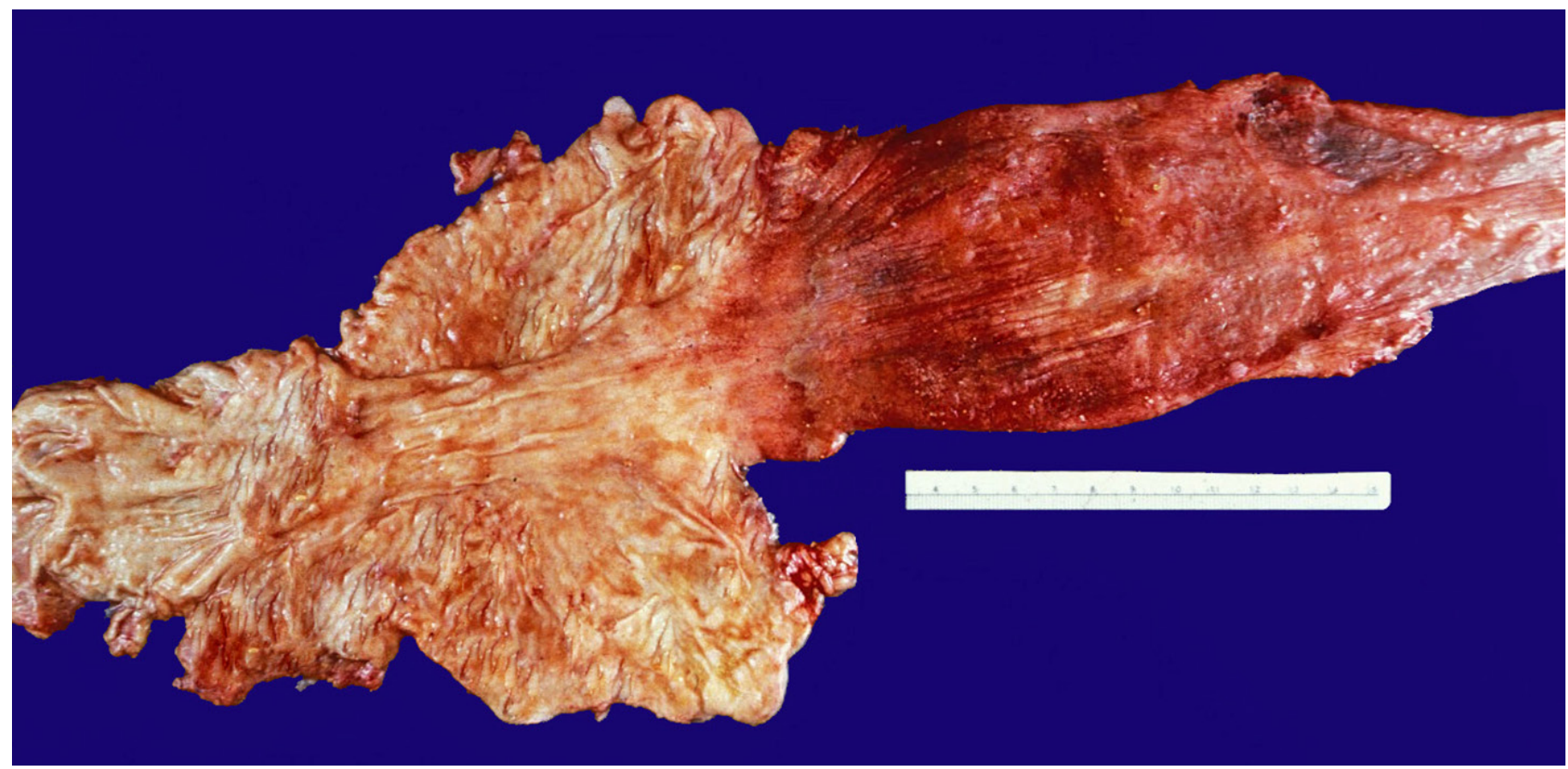

Picture provided by Dr. Stephen A. Geller - personal archive.

Figure 1 - Esophagus (right), stomach, and pylorus with proximal duodenum (left) showing marked esophageal dilation and severe chronic and acute inflamation (esophagitis).

Progressive systemic sclerosis (PSSc) is a chronic disease of unknown etiology characterized by progressive, abnormal accumulation of fibrous tissue in the skin and many organs. Characteristically, there is induration and thickening of the skin (scleroderma), abnormalities involving muscles, joints, and viscera. The first description was likely by William and Robert Watson in 1754 .
In the following century, Robert Graves, in Dublin (1843), and the French physician, Maurice Raynaud (1865), described peripheral vasoconstriction of the hands, relating it to scleroderma, which was present in $90-95 \%$ of the patients with PSSc. It is generally considered that the initiation of PSSc is due to the combined effects of abnormal immune response and vascular damage, leading

\footnotetext{
a Department of Pathology and Laboratory Medicine - Weill Medical College of Cornell University - New York - USA.

${ }^{b}$ Department of Internal Medicine - Hospital Universitário - Universidade de São Paulo, São Paulo/SP - Brazil.

Copyright $\odot 2013$ Autopsy and Case Reports - This is an Open Access article distributed of terms of the Creative Commons Attribution NonCommercial License (http://creativecommons.org/licenses/by/3.0/) which permits unrestricted non-commercial use, distribution, and reproduction in any médium provided article is properly cited.
} 
to local accumulation of growth factors that affect fibroblasts and stimulate collagen production. The vascular involvement in PSSc is not just limited to the microcirculation of the skin, but also is seen in other targeted organs including the heart, lungs, kidneys, and gastrointestinal tract. Clinical and pathological evidence strongly support the concept that the primary insult in targeted organs is directed at blood vessels, and that this injury results in tissue ischemia, fibrosis, and ultimately major organ malfunction. The esophagus was the first visceral organ recognized as being involved in PSSc and it remains the most common site. The alimentary tract is affected in as many as $90 \%$ of patients and any part of the gastrointestinal tract may be involved.

OfPSScpatientswithvisceralinvolvement, 7590\% show esophageal changes, but approximately half of these patients are asymptomatic. Typically, the lower two-thirds of the esophagus has excessive collagenization of the esophageal wall with atrophy and replacement of muscle, particularly the inner circular layer of the muscularis propria. Small arteries often show vasculitis and there is nerve damage due to the vasa nervorum involvement. These alterations sometimes lead to severe narrowing with subsequent reflux and dilation.

The image is of the upper gastrointestinal tract from the autopsy from a 54-year-old woman with long-standing PSSc. The greatly dilated esophagus is to the right and the relatively unremarkable duodenum is to the left, with the similarly unremarkable stomach in the center. The typical "rubber-hose" constriction is not prominent, but the esophagus is narrowed and rigid at the esophagogastric junction, and is greatly dilated with erosions and ulceration, marked chronic inflammation, and thinning of the wall.

Complications of reflux, including Barrett metaplasia and adenocarcinoma, can sometimes be seen, but were not present in this patient. The diagnosis is generally not problematic since other features of PSSc are usually manifest. However, other collagen vascular diseases can also involve the esophagus, including systemic lupus erythematosus, rheumatoid arthritis, polymyositis, dermatomyositis, and mixed connective tissue disorders. The macroscopic changes seen in this case can also occur in achalasia and Chagas megaesopohagus.
Two different physiopathologic mechanisms are recognized in the scleroderma esophageal dysfunction: a) impairment of neuromuscular electrical transmission; and b) progressive loss of muscle strength in the distal esophagus as well as in the lower esophageal sphincter. It is quite likely that the neurological involvement precedes the muscular atrophy and fibrosis.

Dysphagia and pyrosis are the most common symptoms. Likewise, early satiety, regurgitation of food, progressive weight loss, malnutrition, or impaction of food may also be observed. These symptoms are the result of the disruption of peristalsis, gastroesophageal reflux, peptic stricture, and occasionally the presence of candidiasis. The severity of these abnormalities increases with disease progression, establishing a certain parallelism between the intensity of motor problems and disease severity.

Esophageal manometry detects early dysfunction and is altered in $90 \%$ of cases. The most common findings are motor abnormalities, lack or decreased pressure of the distal esophageal high-pressure zone, moderate to severe gastroesophageal reflux, abnormal acid clearance, and decreased frequency of peristaltic contractions. Gastroesophageal reflux rather than impaired motility is the major cause of esophageal symptoms. Endoscopy reveals an atonic esophagus covered by pale mucosa and the presence of ulcers and, often, cicatricial stenosis.

Lateral chest films of patients with scleroderma frequently reveal segmental air or air along the entire esophagus rarely with dilation or air-fluid level; the latter being more suggestive of tumor, stricture, or achalasia.

Keywords: Scleroderma, Systemic; Esophagus.

\section{BIBLIOGRAPHY}

Akesson A, Wollheim FA. Organ manifestations in 100 patients with progressive systemic sclerosis: a comparison between the CREST syndrome and diffuse scleroderma. $\mathrm{Br} \mathrm{J}$ Rheumatol. 1989;28:281. http://dx.doi.org/10.1093/rheumatology/28.4.281

Campbell PM, LeRoy EC. Pathogenesis of systemic sclerosis: a vascular hypothesis. Semin Arthritis Rheum. 1975;4:351-68. http://dx.doi.org/10.1016/0049-0172(75)90017-7 
Dinkler M. Zur lehre von der sklerodermie. Deutsch Arch Klin Med. 1891;48:514-77.

Ducrotté P. Atteinte oesophagienne au cours des maladies systémiques: les dysphagies. Acta Endosc. 2006;36:617-22. French. http://dx.doi.org/10.1007/BF03003764

Garrison FH. An introduction to the history of medicine. 4th ed. Philadelphia: WB Saunders; 1929.

Matucci-Cerinic M, Kahaleh B, Wigley FM. Evidence that systemic sclerosis is a vascular disease. Arthritis Rheum. 2013;65:195362. http://dx.doi.org/10.1002/art.37988
Rocco VK, Hurd ER. Scleroderma and scleroderma-like disorders. Semin Arthritis Rheum.1986;16:22-69.

Savarino E, Mei F, Parodi A, et al. Gastrointestinal motility disorder assessment in systemic sclerosis. Rheumatology. 2013;52:1095100. http://dx.doi.org/10.1093/rheumatology/kes429

Turner R, Lipshutz W, Miller W, et al. Esophageal dysfunction in collagen disease. Am J Med Sci. 1973;265:191.

Vischio J, Saeed F, Karimeddini M, et al. Progression of esophageal dysmotility in systemic sclerosis. J Rheumatol. 2012;39:986-91. http://dx.doi.org/10.3899/jrheum.110923

\section{Stephen A. Geller, M.D.}

Department of Pathology and Laboratory Medicine

Weill Medical College of Cornell University

New York - USA

geller16st@gmail.com

\section{Fernando P. F. de Campos, PhD}

Department of Internal Medicine

Hospital Universitário - USP

São Paulo/SP - Brazil

fpfcampos@gmail.com 
